\title{
Introdução de mini games em um jogo para o ensino do pensamento computacional
}

\author{
Joan G. Tridapalli, Mauro M. Mattos, Luciana P. de Araújo Kohler, Bruno F. F. Santos \\ Heitor Ugarte, Leonardo Fronza, Fabrícia D. Zucco \\ ${ }^{1}$ Laboratório de Desenvolvimento e Transferência de Tecnologias (LDTT) \\ Universidade Regional de Blumenau (FURB) \\ Blumenau - SC - Brasil. \\ \{joangtridapalli, mattos, lpa, bffsantos\}@furb.br \\ \{hucsilveira, leofronza, fabricia\}@furb.br
}

\begin{abstract}
The lack of for digital fluency has led to increased research in Computational Thinking. From research conducted with children between the 1st and 5th grade of elementary school who used a game to learn computational thinking, it was found that there is a lack of stimulation related to gameplay issues that would make the game more attractive and dynamic for them. In this context, three mini games were developed to stimulate children during computational thinking activities and they are available to them between one phase and another.
\end{abstract}

Resumo. A necessidade de fluência digital tem levado ao incremento de pesquisas em Pensamento Computacional (PC). A partir de pesquisas realizadas com crianças entre $1^{\circ}$ e $5^{\circ}$ ano do ensino fundamental, as quais utilizaram um jogo para o aprendizado do pensamento computacional, percebeu-se que falta um estímulo relacionado à questões de jogabilidade que tornariam o jogo mais atrativo e dinâmico para elas. Nesse contexto, desenvolveu-se três mini games para estimular as crianças durante as atividades de pensamento computacional, sendo que os mesmos são disponibilizados a elas entre uma fase e outra.

\section{Introdução}

A necessidade de fluência digital em função da evolução tecnológica experimentada cada vez mais tem motivado uma série de pesquisas no que convencionou-se chamar de Pensamento Computacional (PC). O pensamento computacional introduz uma nova abordagem para a área da Ciência Cognitiva e da Ciência da Computação, pois parte da premissa de que a inserção dos conceitos da Ciência da Computação na educação básica desenvolve uma habilidade de abstração diferente, a qual ajuda as crianças na resolução de problemas em todas as áreas da vida. Conforme [Wing 2006], o Pensamento Computacional é um dos conhecimentos e habilidades necessárias para a cidadania no século XXI, sendo que o mesmo pode relacionar-se a diversas áreas do saber

Já [Brackmann 2017] afirma que esta é uma nova abordagem que parte da premissa de que a inserção dos conceitos da Ciência da Computação na educação básica possibilita o desenvolvimento de habilidades que podem ajudar as crianças na resolução de problemas em todas as áreas da vida, seja de maneira individual ou colaborativa. 
VIII Congresso Brasileiro de Informática na Educação (CBIE 2019)

Anais dos Workshops do VIII Congresso Brasileiro de Informática na Educação (WCBIE 2019)

Nesse contexto, a Sociedade Brasileira de Computação (SBC) propôs que a Computação seja inserida na grade do ensino básico até o ensino médio, incluindo as escolas públicas sendo que se deve trabalhar, na educação infantil, habilidades voltadas à compreensão de problemas, identificação de sequência de passos, representação de passos de forma relacionada e organizada e sequenciamento de passos relacionados à movimentação de corpos e trajetos espaciais [SBC 2017]. Já no ensino fundamental, do $1^{\circ}$ ao $5^{\circ}$ ano, deve-se trabalhar as habilidades relacionadas ao desenvolvimento de abstração de experiências concretas descritas através de dados e listas, identificação de estruturas condicionais e de repetição, uso de linguagens lúdicas para representação de algoritmos, compreensão sobre como decompor um problema para soluciona-lo em pedaços. A partir do $6^{\circ}$ ano ao $9^{\circ}$ ano, a recomendação é que seja introduzida uma linguagem de programação nativa para representação de dados e processos, além da formalização dos conceitos em estruturas de dados, uso de recursões e generalizações [Raabe et al. 2017].

Levando em consideração o atual cenário da Educação Básica no país em que há escassez de recursos de toda a ordem, ensinar habilidades computacionais pode, portanto, configurar-se como um desafio. Ao mesmo tempo, apresenta-se um cenário repleto de oportunidades aos educadores, pesquisadores e à comunidade escolar. É neste contexto que se introduz a plataforma para o ensino do pensamento computacional apresentada neste artigo. Conforme [Araújo et al. 2018] Uma das maneiras de motivar estudantes e o uso da técnica de gamification, ou seja, a adoção de uma estratégia de interação com base na oferta de estímulos que favoreçam o engajamento de uma maneira lúdica.

Dentre várias plataformas existentes para facilitar o aprendizado de lógica de programação, a plataforma desenvolvida foi concebida para minimizar as dificuldades de aprendizagem e ensino na lógica de programação por meio de um forte apelo a área de jogos, criando assim uma atmosfera facilitadora ao aprendizado. $\mathrm{O}$ elemento central do ambiente e a programação de um robô que vive em um mundo bidimensional junto de outros tipos de objetos, os quais também podem ser programados. Sobre esse mundo, o aluno desenvolve atividades de movimentação em quatro direções e também de detecção de obstáculos. Esses exercícios evoluem em grau de dificuldade conforme a evolução do estudante, a ponto de possibilitar o desenvolvimento de um jogo completo.

Inserido no contexto do ensino fundamental desde 2017, a plataforma busca promover inclusão digital cidadã por meio de oficinas de programação que permitam o desenvolvimento de aptidões em pensamento computacional. Várias observações vêm sendo realizadas durante as intervenções em sala de aula com crianças e um dos aspectos que tem chamado a atenção é o fato das crianças preferirem jogar outros jogos da internet. Dessa forma, decidiu-se desenvolver mini games para transitarem entre uma fase e outra do jogo referente ao pensamento computacional, sendo estes mais lúdicos, com o objetivo de atrair mais as crianças a se manterem no jogo.

Sendo assim, o artigo segue dividido da seguinte forma. A seção 2 descreve o jogo atual que ensina o pensamento computacional. A seção 3 aborda sobre os mini games projetados para inclusão entre uma fase e outra do jogo principal. A seção 4 discorre sobre os resultados alcançados até o momento pela inclusão dos mini games na plataforma. Por fim, a seção 5 conclui o artigo e apresenta o trabalhos futuros. 
VIII Congresso Brasileiro de Informática na Educação (CBIE 2019)

Anais dos Workshops do VIII Congresso Brasileiro de Informática na Educação (WCBIE 2019)

\section{Jogo Atual}

A plataforma atual e desenvolvida utilizando como base um framework Java existente há aproximadamente 10 anos e foi concebida para apoiar as atividades de ensinoaprendizagem da disciplina de Introdução a Programação nos cursos de graduação em Ciência da Computação e Sistemas de Informação, sendo utilizado nos últimos anos por mais de 500 alunos. A partir de 2017 foi adaptado para ser utilizado no desenvolvimento de habilidades de Pensamento Computacional em crianças de $1^{\circ}$ ao $5^{\circ}$ ano de uma escola pública do município [Araújo et al. 2018]. A plataforma foi adaptada para ser um jogo, pois uma das maneiras de motivar estudantes é o uso da técnica de jogos digitais (ou gamification), ou seja, a adoção de uma estratégia de interação com base na oferta de estímulos que favoreçam o engajamento de uma maneira lúdica.

O elemento central do jogo é a programação de um robô que vive em um mundo bidimensional (Figura 1) junto de outros tipos de objetos os quais também podem ser programados. Sobre esse mundo, o aluno desenvolve atividades de movimentação em quatro direções e de detecção de obstáculos. Esses exercícios evoluem em grau de dificuldade conforme a evolução do estudante, introduzindo os diferentes conceitos de pensamento computacional conforme recomendado pelas diretrizes da SBC.

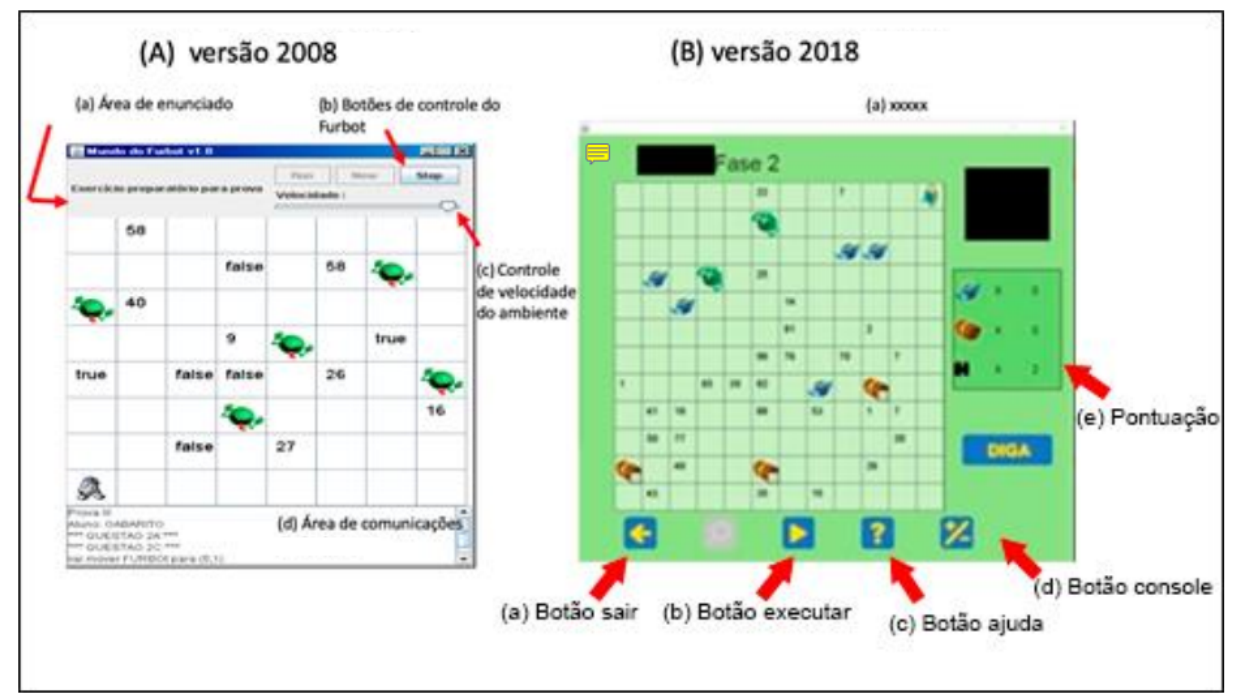

Figura 1. Jogo versão Java

Após experimentos realizados e relatados em [Mattos et al. 2018], decidiu-se transformar a plataforma existente em uma plataforma com maiores aspectos de jogo, incluindo roteiros e outras questões de jogabilidade. Decidiu-se então, desenvolver este jogo na plataforma Unity, modernizando os cenários, porém mantendo a ideia de programar o robô para passar de fases.

Nesse contexto, a concepção da versão em Unity envolveu um completo redesenho da arquitetura do projeto introduzindo-se um apelo mais forte à gamificação [Mattos et al. 2018]. A Figura 2 apresenta a tela inicial do jogo e uma sequência de fases envolvendo diversas áreas do mundo, sendo: Amazônia (b), deserto (c), gelo (d) e a fase final onde há a disputa com um personagem chamado de "Rei Buggien" (e).

Nesta versão, para viabilizar a movimentação do robô, é necessário construir uma 
VIII Congresso Brasileiro de Informática na Educação (CBIE 2019)

Anais dos Workshops do VIII Congresso Brasileiro de Informática na Educação (WCBIE 2019)

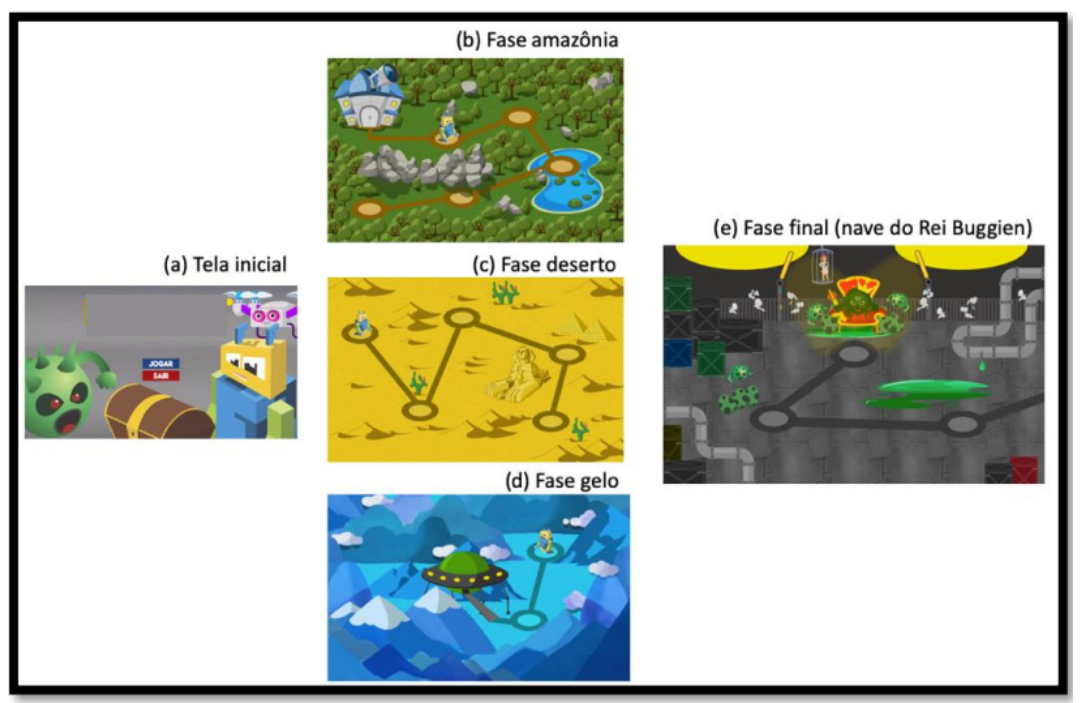

Figura 2. Jogo em Unity

sequência lógica de passos. A Figura 3 apresenta a interface, em que o jogador pode introduzir (e editar) a sequência de comandos que serão executados pelo personagem. $\mathrm{Na}$ base da tela é possível controlar o número de vidas, a quantidade de energia (o robô perde energia quando caminha e também quando bate em obstáculos, sendo que a programação precisa ser alterada para capturar-se energia suficiente para concluir uma fase), o número de tesouros obtidos, vidas e outros elementos pertencentes à história do jogo.

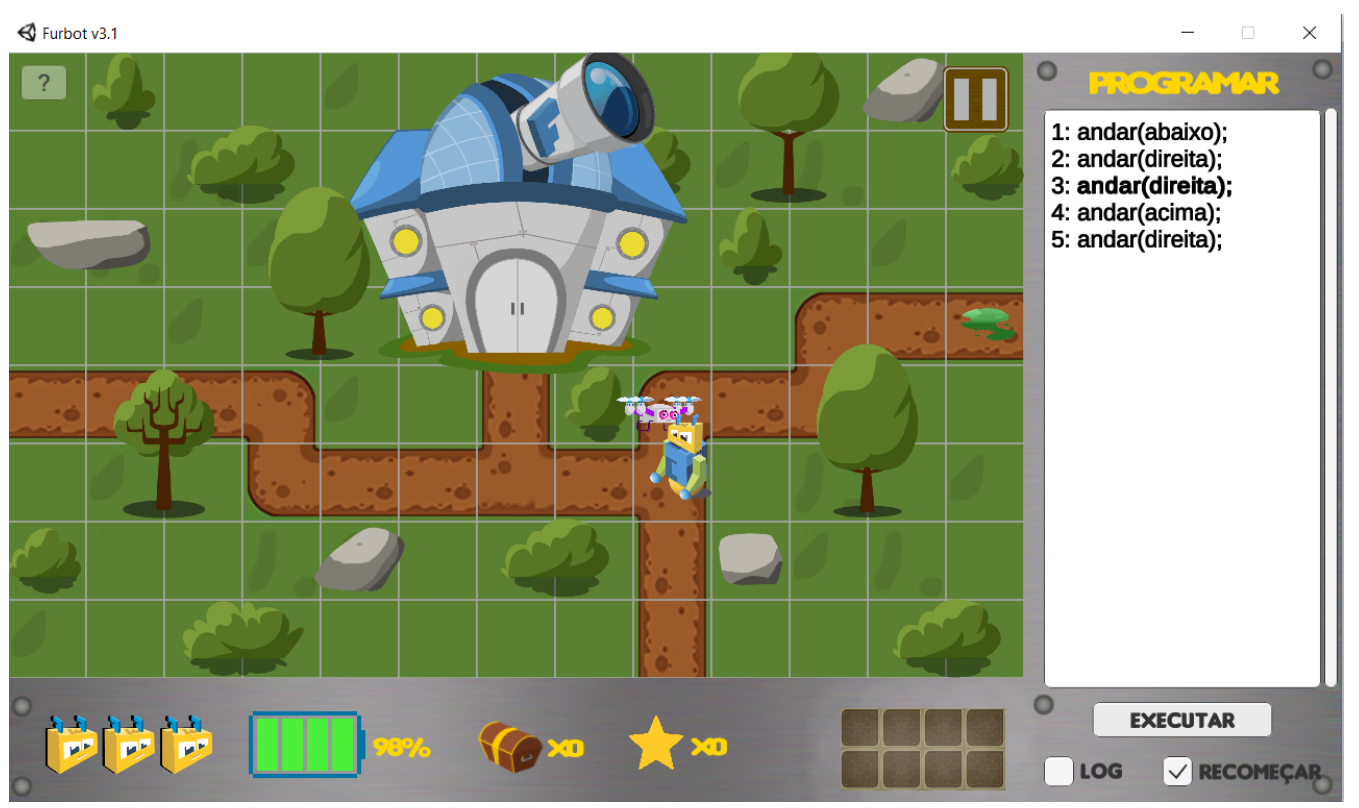

Figura 3. Interface do jogo

As fases do jogo são acessadas através do mapa principal (Figura 2), em que o jogador pode escolher a fase que deseja ir, sendo preciso desbloqueá-las em sequência. $\mathrm{O}$ conceito principal do jogo segue conforme o diagrama de atividades na Figura 4, em que o jogador ao entrar no jogo se depara com o mapa para selecionar as fases, ao terminar uma delas terá a opção de reiniciá-la ou voltar ao mapa para ir à próxima. 
VIII Congresso Brasileiro de Informática na Educação (CBIE 2019)

Anais dos Workshops do VIII Congresso Brasileiro de Informática na Educação (WCBIE 2019)

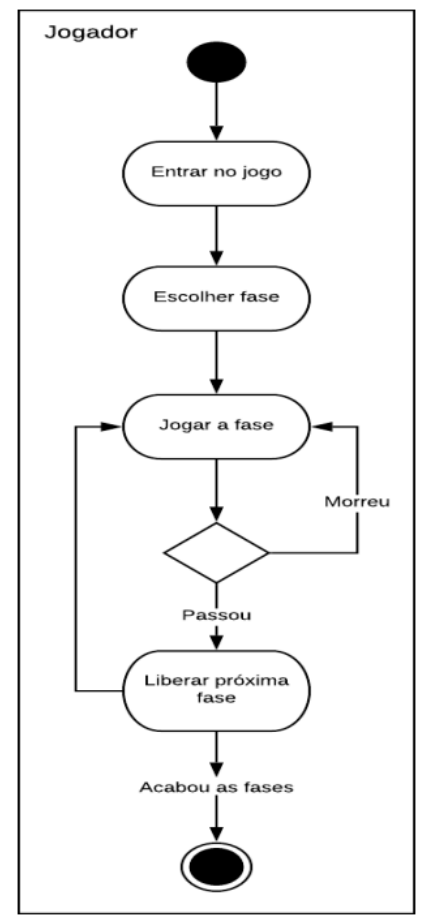

Figura 4. Diagrama de atividades

\section{Mini games}

Com o intuito de inserir um contexto em que o nível de gamificação é mais acentuado, a estratégia utilizada foi o desenvolvimento de pequenos jogos visando levar a criança a brincar sem a preocupação de desenvolver uma estratégia relacionada ao jogo principal do pensamento computacional. Para isto, foram desenvolvidos 3 jogos, os quais foram inseridos após cada fase padrão.

O primeiro jogo foi baseado no esporte cabo de guerra, que consiste em dois times segurando um cabo e o puxando e direções opostas. O time que fizer o outro cruzar a linha entre eles primeiro vence. Este primeiro jogo utiliza como protagonistas de um lado o personagem principal do jogo, o robô, e um drone chamado S223 e, de outro, os antagonistas Buggien e o Rei Buggien. Para fazer com que os protagonistas puxem o cabo, quadrados com setas passam na parte de cima da tela, e o usuário deve apertar o direcional do teclado correspondente na hora em que o quadrado passar na marcação, conforme mostrado na Figura 5. Os comandos foram criados desta forma buscando melhorar as habilidades cognitivas associadas ao reflexo.

O segundo jogo (Figura 6) tem como objetivo completar a palavra com base em uma pergunta. A resposta para a pergunta deve ser montada como um quebra-cabeças. No protótipo foram selecionadas dez perguntas, cujas respostas são as peças. A escolha das perguntas foi realizada sob orientação de uma educadora pedagógica, bem como com base na Base Nacional Comum Curricular [BNCC 2018]. Na cena há mais letras do que a quantidade necessárias para compor a palavra, para estimular a criança a ter a percepção de um elemento em meio a um conjunto.

Por fim, o terceiro jogo busca trabalhar o aspecto de conscientização das crianças sobre a importância da reciclagem. Neste jogo o vilão, o Rei Buggien, está em sua 
VIII Congresso Brasileiro de Informática na Educação (CBIE 2019)

Anais dos Workshops do VIII Congresso Brasileiro de Informática na Educação (WCBIE 2019)

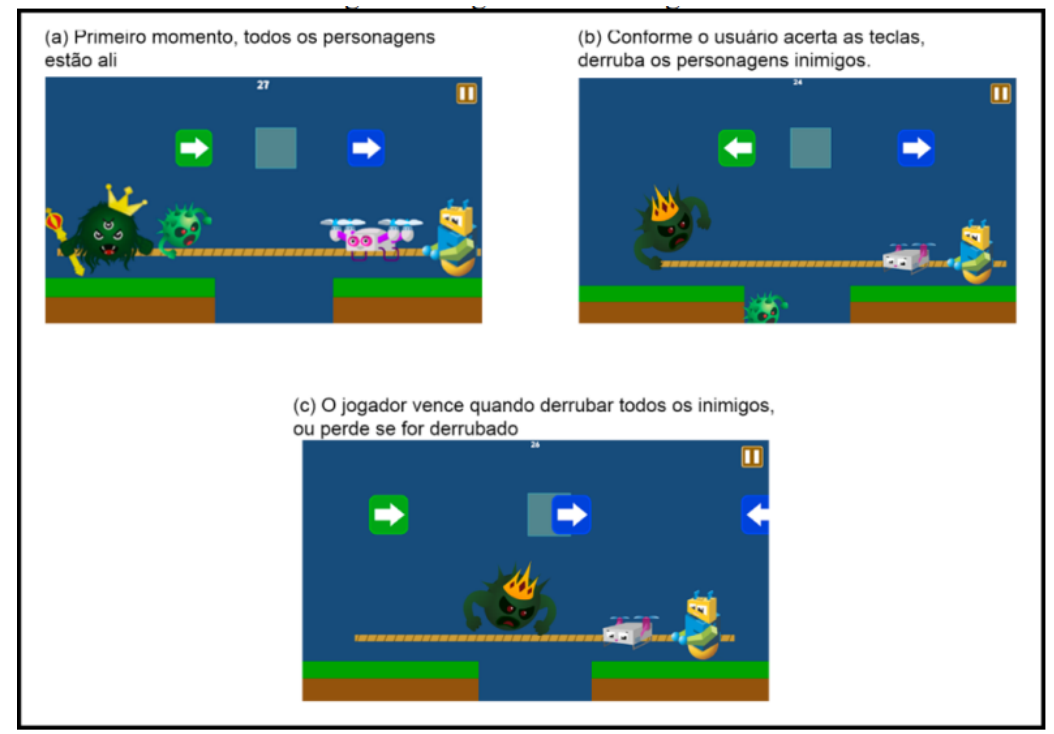

Figura 5. Jogo 1 - Cabo de guerra

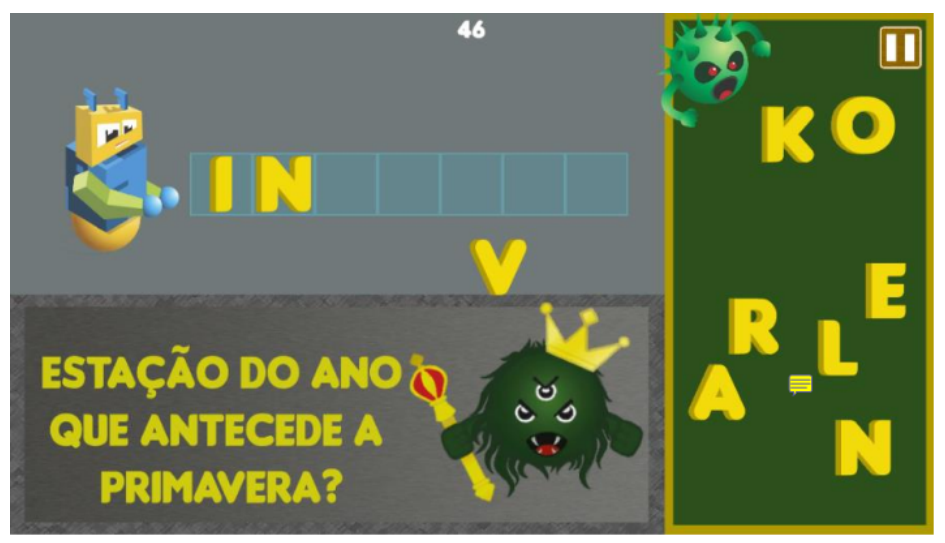

Figura 6. Jogo 2 - Caça palavras

espaçonave jogando lixo na direção do robô que precisa ficar em frente a lata de lixo correspondente para ganhar pontos (Figura 7). Se o aluno errar três vezes o jogo encerra. A movimentação do robô ocorre com base no eixo horizontal da tela, sendo que no computador as teclas correspondentes a movimentação são as setas esquerda e direita ou as letras A e D. Já na plataforma móvel, corresponde a apertar do lado esquerdo ou direito da tela. A geração do lixo que é atirado pela espaçonave é gerada de forma aleatória, sendo feita a detecção dos objetos com base no sistema de colisão da Unity.

\section{Resultados}

Para testar os mini games desenvolvidos, realizou-se uma oficina com crianças que já conhecem a plataforma anterior sem a versão dos mini games. A oficina foi realizada em uma associação com oito crianças de 8 a 11 anos e teve duração total de uma hora.

Cada criança recebeu o novo jogo e pode utiliza-lo individualmente durante um período de 40 minutos. Nesse período, as crianças resolviam as atividades do pensamento computacional e, entre uma fase e outra, jogavam os mini games. Como os mesmos não 
VIII Congresso Brasileiro de Informática na Educação (CBIE 2019)

Anais dos Workshops do VIII Congresso Brasileiro de Informática na Educação (WCBIE 2019)

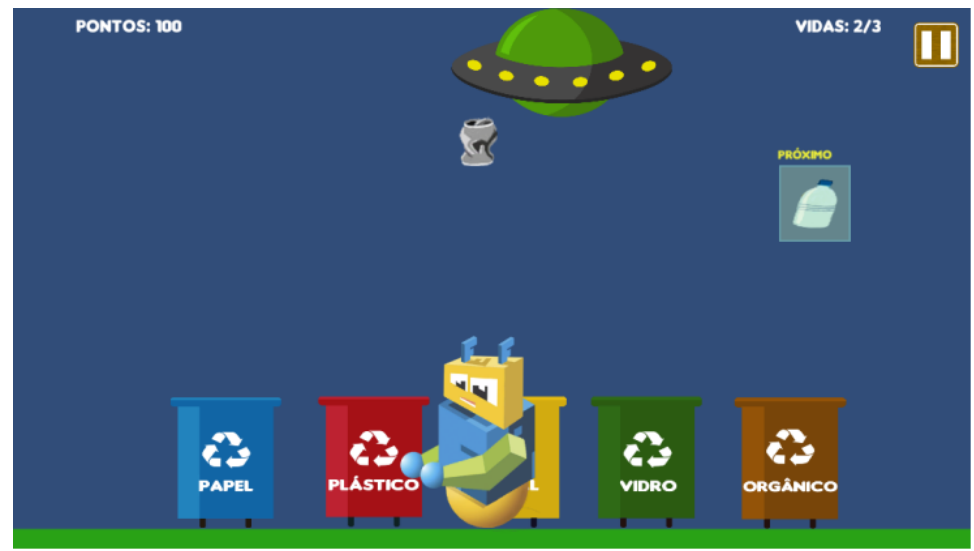

Figura 7. Jogo 3 - Coleta de lixo

possuíam um tutorial sobre como joga-lo, elas foram previamente instruídas a respeito do funcionamento de cada um dos jogos.

Após o uso, cada criança foi questionada individualmente a respeito do que achou dos jogos. Todas as crianças mostraram que se divertiram com os jogos entre uma fase e outra. Elas falaram que gostaram, pois fica algo diferente além de resolver o problema sobre o pensamento computacional. Nesse momento, elas podem descansar um pouco a mente, porém continuam aprendendo e treinando outras habilidades cognitivas sem perceber.

\section{Conclusões e Trabalhos Futuros}

O jogo em questão é um projeto que possui um grande potencial para permitir o desenvolvimento de habilidades em Pensamento Computacional. O esforço realizado durante aproximadamente 10 anos permitiu a equipe do projeto acumular um agregado de experiências que estão sendo totalizadas na atual versão do projeto.

Pretende-se aplicar esta versão em escolas, afim de realizar novos testes. A partir disso, espera-se ampliar os resultados obtidos até o momento. Como este foi um projeto piloto, novas versões deverão ser desenvolvidas. Assim sugere-se: melhorias na mecânica dos atuais mini-jogos e incremento na possibilidade de inclusão de novos mini-jogos; desenvolvimento de uma versão que possibilite jogos em grupos de alunos; possibilidade de alteração da estrutura da engine para permitir a atualização dos desafios a partir de um servidor remoto.

\section{Referências}

Araújo, L., da Silveira, H. U. C., e Mattos, M. (2018). Ensino do pensamento computacional em escola pública por meio de uma plataforma lúdica. In Anais dos Workshops do VII Congresso Brasileiro de Informática na Educação (CBIE 2018). Brazilian Computer Society (Sociedade Brasileira de Computação - SBC).

BNCC (2018). Base nacional curricular comum. disponível em: http://basenacionalcomum.mec.gov.br/abase/. 
VIII Congresso Brasileiro de Informática na Educação (CBIE 2019)

Anais dos Workshops do VIII Congresso Brasileiro de Informática na Educação (WCBIE 2019)

Brackmann, C. P. (2017). Desenvolvimento do pensamento computacional através de atividades desplugadas na educação básica. Tese, Universidade Federal do Rio Grande do Sul.

Mattos, M., Araújo, L., da Silveira, H. U. C., Schlögl, L., Giovanella, G. C., Santos, B., Fronza, L., Zucco, F., Hein, N., de Oliveira, G. C., da Cunha, K. Z., e Sartori, A. (2018). Uma pesquisa-ação sobre o desenvolvimento do pensamento computacional com crianças. In Anais do XXIV Workshop de Informática na Escola (WIE 2018). Brazilian Computer Society (Sociedade Brasileira de Computação - SBC).

Raabe, A., Santana, A. L. M., Ellery, N., e Gonçalves, F. (2017). Um instrumento para diagnóstico do pensamento computacional. In Anais dos Workshops do VI Congresso Brasileiro de Informática na Educação (CBIE 2017). Brazilian Computer Society (Sociedade Brasileira de Computação - SBC).

SBC (2017). Referenciais de formação em computação: Educação básica. disponível em: https://www.sbc.org.br/noticias/10-slideshow-noticias/1996-referenciais-deformacao-em-computacao-educacao-basica.

Wing, J. M. (2006). Computational thinking. Commun. ACM, 49(3):33-35. 